\title{
Originals
}

\section{Evaluation of an intensified insulin treatment and teaching programme as routine management of Type 1 (insulin-dependent) diabetes}

\author{
The Bucharest-Duisseldorf Study
}

\author{
I. Mühlhauser ${ }^{2}$, I. Bruckner ${ }^{1}$, M. Berger ${ }^{2}$, D.Cheţa ${ }^{1}$, V.Jörgens ${ }^{2}$, C. Ionescu-Tîrgovişte ${ }^{1}$, V.Scholz $^{2}$ and I. Mincu ${ }^{1}$ \\ Departments of Nutrition and Metabolism of the University Hospitals of ${ }^{1}$ Bucharest, Rumania, and ${ }^{2}$ Düsseldorf, FRG
}

\begin{abstract}
Summary. It has been questioned whether aiming at nearnormoglycaemia by intensified insulin treatment regimens is feasible and safe for the majority of patients with insulin-dependent diabetes. In this study, intensified insulin injection therapy (including blood glucose self-monitoring and multiple insulin injections) based upon a 5-day inpatient group teaching programme was evaluated in Type 1 (insulin-dependent) diabetes mellitus in the centralised health care system of Bucharest. One hundred patients (group A, initial $\mathrm{HbA}_{1}$ $12.5 \%$ ) were followed for 1 year on their standard therapy (individual teaching, no metabolic self-monitoring), and thereafter for 1 year on intensified therapy. Another 100 patients (group $\mathrm{B}, \mathrm{HbA}_{1} \mathrm{12.3 \%}$ ) were followed for 2 years on intensified therapy. A third 100 patients (group C, $\mathrm{HbA}_{1}$ $11.7 \%$ ) were assigned to a basic 4-day inpatient group teaching programme with conventional insulin therapy (including self-monitoring of glucosuria and acetonuria) and followed for 1 year. Mean $\mathrm{HbA}_{1}$ remained unchanged after standard treatment (group A: $12.8 \%$ at 12 months), but decreased dur-
\end{abstract}

ing intensified therapy (group A: $10.1 \%$ at 24 months; group B: $9.3 \%$ at 12 months, $9.5 \%$ at 24 months; $p<0.0001$ ). In group $C$, no change was found compared to standard treatment (i.e. group A at 12 months). Incidence rates of ketoacidosis were 0.16 episodes per patient per year during standard treatment, 0.01 during intensified treatment $(p<$ $0.01)$ and 0.04 in group $C(p<0.025)$. Hospitalisation rates were reduced by $60 \%$ during intensified therapy and by $40 \%$ in group C. Frequency of severe hypoglycaemia was not significantly different between the three treatment regimens. Thus, under the condition that insulin treatment is based upon a structured and comprehensive training of the patient, intensified insulin injection therapy performed as routine treatment of Type 1 diabetes significantly lowers $\mathrm{HbA}_{1}$ levels without increasing the risk of severe hypoglycaemia.

Key words: Type 1 diabetes, insulin therapy, severe hypoglycaemia, ketoacidosis, patient education.
Conventional therapy of Type 1 (insulin-dependent) diabetes is associated with substantially increased morbidity and mortality rates due to hyperglycaemia-induced organ damage [1]. During the last decade nearnormalisation of blood glucose has become technically feasible. A number of studies have shown that selected patients can be trained to combine blood glucose selfmonitoring with intensified insulin substitution regimens to maintain lower blood glucose levels than could hitherto be achieved with conventional treatment strategies [2-4]. However, concern has been raised about the possibility of extending intensive insulin treatment methods to large numbers of patients without increasing the risk of severe hypoglycaemia or health care costs $[5,6]$. Furthermore, there has been doubt that intensive regimens are acceptable or practi- cable for the majority of insulin-treated diabetic patients or their health care providers [6].

At the University Hospital of Düsseldorf intensive insulin treatment based upon a structured and comprehensive 5-day inpatient group teaching programme has been standard therapy for all Type 1 diabetic patients since 1978. Practicability, safety and long-term effectiveness of this intervention have been documented repeatedly [7-9]. However, none of these trials were controlled investigations, and it could be argued that the patients studied may not be representative of Type 1 diabetic populations in general.

Therefore, the same intensive diabetes treatment and teaching programme was evaluated in a prospective controlled trial carried out in the centralised 
health care system of Bucharest, where the University Hospital provides care for all diabetic patients of the city and its surroundings.

\section{Subjects and methods}

\section{Patients and protocol}

A total of 300 Type 1 (ketosis-prone, insulin-dependent) diabetic patients consecutively admitted to the diabetes ward of the University Hospital of Bucharest and aged 15 to 40 years agreed to participate. They were informed about the nature of the study, i.e. the controlled introduction of established treatment strategies into their health care system and the possibility of a limitation of imported materials for metabolic self-monitoring after completion of the study was made known to the patients. Patients were hospitalised due to metabolic decompensation or for initiation of insulin treatment when diabetes was newly diagnosed. Exclusion criteria were: admission primarily because of severe acute or chronic disorders unrelated to diabetes, mental retardation or psychiatric diseases that would interfere with participation of the patient in a group teaching programme, clinically overt diabetic nephropathy (urinary protein excretion exceeding $0.5 \mathrm{~g} /$ day and/or raised serum creatinine levels), proliferative retinopathy or blindness, or severe foot complications. Patients were group randomised [10] to 3 different treatment regimens. The first consecutive 100 patients meeting the eligibility criteria (group A) continued the standard treatment of the Bucharest Hospital during the first year of the study. Thereafter, they participated in the intensive diabetes treatment and teaching programme (IDTTP) and were followed for another year. The second 100 patients (group B) participated in the IDTTP immediately after their recruitment into the study and were followed for 2 years. The last 100 patients (group C) were assigned to a basic diabetes treatment and teaching programme (BDTTP) and were followed for 1 year. The recruitment of all patients was completed within 1 year.

\section{Diabetes treatment and diabetes teaching programmes}

The diabetes unit of the Bucharest University Hospital consists of an inpatient and an outpatient department which are located in separate buildings. During their assignment to the outpatient clinic, physicians working there have no duties on the diabetes ward, and viceversa. The decision about a patient's admission to the diabetes ward is made by the physicians of the outpatient department, but emergency cases may be directly hospitalised. Traditionally, Type 1 diabetes is managed in the following way (standard treatment): for initiation of insulin therapy or restabilisation of metabolic control, patients are hospitalised for about 1 week. Insulin therapy is performed with a variety of bovine and porcine insulin preparations of North American and European companies (Novo and Nordisk, Copenhagen, Denmark; Hoechst, Frankfurt, FRG; Eli Lilly, Indianapolis, Ind, USA). In addition, less purified Rumanian insulin preparations are used (Biofarm, Bucharest, Rumania). Generally, patients inject an intermediate acting insulin twice daily, or a combination of intermediate and rapid acting insulins twice daily. Patients are not supposed to adjust insulin dosages by themselves, and metabolic self-monitoring is not advised. A traditional diabetes diet, rigid with respect to timing and amount of carbohydrate intake, is prescribed. Instruction of the patients about the management of their disease is performed individually by the physician in charge. After discharge, patients must regularly visit the outpatient unit in order to get insulin prescribed.

The IDTTP was identical to that of the University Hospital of Düsseldorf [7-9]. Two physicians (I.B., D.C.) and two nurses had come to Düsseldorf during May 1984 for 2 weeks' training in order to perform the programme in Bucharest. The teaching was delivered by the two nurses in a structured Monday to Friday inpatient course for groups of about 10 patients. The goal of the IDTTP is to motivate and enable the patients to strive for blood glucose values as nor$\mathrm{mal}$ as possible, i.e. preprandial glycaemia around $5.5 \mathrm{mmol} / \mathrm{l}$. Important general prerequisites for achieving optimal metabolic control are: 3-4 times daily preprandial and bedtime metabolic self-monitoring of either blood glucose or urine glucose concentrations; insulin therapy with at least two injections per day using miscible intermediate and rapid acting insulin preparations; adaptation of the insulin dosage by the patients themselves without previously contacting a physician; and recording results of metabolic self-monitoring, insulin dosages, hypoglycaemic episodes or other events relevant to glycaemic regulation in a diabetes $\log$ book. Under the condition that insulin treatment is intensified, patients may liberalise their diet. This includes variation of amount and timing of carbohydrate intake, skipping of meals altogether and a prudent consumption of sucrose and sucrose containing nutrients [11-13]. The more liberalised the diet becomes, the more frequent measurements of blood glucose and the more frequent injections of regular insulin and immediate adaptations of insulin dosage will be necessary to keep glycaemia in optimal control.

In the present study, all patients who participated in the IDTTP were treated with Monotard MC and Actrapid MC (Novo, Copenhagen, Denmark). The patients were provided with sufficient material to perform 3 to 4 times daily blood glucose or urine glucose measurements and determinations of acetonuria if indicated. The materials used were Chemstrip 20-800, Diabur-Test 5000 and KeturTest, respectively (Boehringer Mannheim, Mannheim, FRG). In addition, patients received glucagon sets (Glucagon, Novo, Copenhagen, Denmark) for subcutaneous or intramuscular application [14] in cases of severe hypoglycaemia with loss of consciousness. Whenever possible, relatives of the patients were trained personally by the nurse educators in the usage of the injection set; otherwise relatives were instructed by the patients themselves. All 300 patients received plastic syringes (Plastipak, Becton and Dickinson, Heidelberg, FRG) and were instructed to use one syringe per day throughout the study. Patients who had participated in the IDTTP were exclusively followed-up by the specially trained team of two physicians and two nurses at a place separate from the general outpatient clinic.

The BDTTP included metabolic self-monitoring with materials produced in Rumania. For self-monitoring of glucosuria a semiquantitative impregnated paper test strip method (Glucozuriei, Laboratorul Galenic, Bucharest, Rumania) was used. The method is based upon the reduction of copper sulfate to cuprous oxide, and requires heating at $105^{\circ} \mathrm{C}$ for about $15 \mathrm{~min}$. The reliability of the method is acceptable with a good sensitivity between $0.5 \mathrm{~g} / \mathrm{dl}$ $(27.8 \mathrm{mmol} / \mathrm{l})$ and $2.5 \mathrm{~g} / \mathrm{dl}(138.9 \mathrm{mmol} / \mathrm{l})$, but false positive readings may be obtained at concentrations lower than $0.1 \mathrm{~g} / \mathrm{dl}$ $(5.6 \mathrm{mmol} / \mathrm{s})$ and false low values at concentrations above $2.5 \mathrm{~g} / \mathrm{dl}$ $(138.9 \mathrm{mmol} / \mathrm{l})$ [15]. For testing of acetonuria, reagent tablets (Acetotest, Bucharest, Rumania) were used. Insulin therapy was performed with various insulin preparations as in the standard therapy regimen. The teaching programme was a modification of the intensive programme; it lasted 4 days and was delivered by the two teaching nurses. The goal of the therapy was aglucosuria without significant hypoglycaemic reactions. Simple rules for self-adjustment of insulin dosages were provided, and patients were trained to match their diet to the insulin preparation used. The patients were followed-up in the general diabetic outpatient unit by various physicians; in addition, they had the possibility of contacting the two physicians and the two nurses of the diabetes treatment and teaching team.

\section{Procedures}

Patients of groups A and B were evaluated at entry into the study after metabolic recompensation, and after $6,12,18$ and 24 months. Group $\mathrm{C}$ was followed for only 12 months. Glycosylated haemoglobin $\left(\mathrm{HbA}_{1}\right)$ was measured using a microcolumn method (Boehringer Mannheim, Mannheim, FRG), the normal range (mean $\pm 2 \mathrm{SD}$ of 50 healthy subjects) being 5.4 to $7.6 \%$. Fasting serum C-peptide was measured at entry into the study using a commercially available ra- 
dioimmunoassay (IRE, Fleurus, Belgium) and a value $\geq 0.17 \mathrm{nmol} / 1$ was considered positive. Serum insulin antibodies were assessed by a radioimmunological method as described elsewhere [16]. Specific binding (presence of insulin antibodies) was assumed to be present for values $>8 \%$. Severe hypoglycaemia and ketoacidosis were assessed by standardised interview and by a review of patient records. Severe hypoglycaemia was defined as loss of consciousness treated either by intravenous glucose administration or glucagon injection. Ketoacidosis was defined as a hyperglycaemic ketotic metabolic decompensation associated with clinical signs of ketoacidosis, an arterial $\mathrm{pH}$ value below 7.3, and treatment provided in the hospital. Hospitalisations were evaluated by analysing patient records. If a patient had been treated in another hospital, e.g. for surgery, a report was requested. All hospitalisations, diabetes-related or not, were included in the analyses. Diabetes-related knowledge was assessed using an illustrated questionnaire with 37 questions on general aspects of diabetes, metabolic self-monitoring, rules for changing insulin dose, treatment and prevention of hypoglycaemia, and diet. The total internal reliability of the questionnaire was 0.8 [7]. In addition, rates of compliance with the following items of the teaching and treatment programme were evaluated: (1) patients were asked to demonstrate that they were carrying emergency carbohydrates for treatment of hypoglycaemia; (2) they were asked to present their diabetes log books; (3) frequencies of metabolic self-monitoring were assessed by analysing the log book entries concerning the last 4 weeks before the follow-up examination; (5) performance of glucagon administration by relatives in case of severe hypoglycaemia was evaluated by patient interview and the number of glucagon sets delivered to the patients.

\section{Statistical analysis}

Data are expressed as means \pm SEM unless indicated otherwise. Patient characteristics at entry were compared by parametric and nonparametric tests for unpaired data (Student's t-test, one-way analysis of variance, Wilcoxon rank sum test, Kruskal-Wallis 1-way ANOVA) [17]. For quantitative outcome measures, groups were compared at each time point by the Wilcoxon rank sum test and the Kruskal-Wallis 1-way ANOVA, respectively. A special procedure has been adopted to adjust for the baseline differences in $\mathrm{HbA}_{1}$ levels [17]. To assess change over time within the groups, the paired samples t-test, analyses of variance for repeated measurements, the Wilcoxon matchedpairs signed-ranks test and the Friedman two-way ANOVA were applied. The chi-square test (with Yates correction, if indicated) was used for variables involving categorical classifications (e.g. frequency of severe hypoglycaemia and ketoacidosis). The McNemar test was used to compare the frequencies of these complications between the first and second year of follow-up. Statistical significance was assumed at a two-tailed $p<0.05$.

\section{Results}

\section{Comparability and follow-up of the groups}

At entry into the study, characteristics of the 3 patient groups (Table 1) were not statistically different, with the exception of $\mathrm{HbA}_{1}$ values, which were lower in group $\mathrm{C}(p<0.05)$. In group $\mathrm{A}$, there were 4 deaths during the year of standard treatment. One patient died in hypoglycaemia associated with alcohol intake, and 3 patients died after hospitalisation in a state of severe ketoacidosis accompanied by pneumonia, endocarditis and septicaemia, respectively. One patient had moved away from Bucharest and 2 patients refused to come to the follow-up examinations. After the first
Table 1. Characteristics of the three patient groups at entry into the study

\begin{tabular}{|c|c|c|c|}
\hline & Group A & Group B & Group C \\
\hline Total no. of patients & 100 & 100 & 100 \\
\hline Female sex (no.) & 40 & 43 & 46 \\
\hline Age (years) & $26(1)$ & $26(1)$ & $26(1)$ \\
\hline \multicolumn{4}{|l|}{$\begin{array}{l}\text { Occupation of patients } \\
\text { (no.) }\end{array}$} \\
\hline Blue collar workers & 43 & 42 & 39 \\
\hline White collar workers & 27 & 31 & 30 \\
\hline Students & 24 & 22 & 20 \\
\hline Others & 6 & 5 & 11 \\
\hline $\begin{array}{l}\text { Body mass index } \\
\left(\mathrm{kg} \cdot \mathrm{m}^{-2}\right)\end{array}$ & $21.7(0.3)$ & $21.8(0.2)$ & $21.5(0.2)$ \\
\hline $\begin{array}{l}\text { Patients with newly } \\
\text { diagnosed diabetes } \\
\text { (no.) }\end{array}$ & 11 & 13 & 10 \\
\hline $\begin{array}{l}\text { Median duration of } \\
\text { diabetes (years) }^{\mathrm{a}}\end{array}$ & 5 & 6 & 5 \\
\hline $\begin{array}{l}\text { C-peptide positive } \\
\text { patients (no.) }\end{array}$ & 12 & 15 & 20 \\
\hline $\begin{array}{l}\text { Patients with insulin } \\
\text { antibodies (no.) }\end{array}$ & 48 & 49 & 50 \\
\hline $\begin{array}{l}\text { Glycosylated } \\
\text { haemoglobin }\left(\mathrm{HbA}_{1}, \%\right)\end{array}$ & $12.5(0.2)$ & $12.3(0.2)$ & $11.7(0.2)^{b}$ \\
\hline $\begin{array}{l}\text { Patients with a history } \\
\text { of severe } \\
\text { hypoglycaemia (no.) }\end{array}$ & 17 & 23 & 19 \\
\hline $\begin{array}{l}\text { Daily insulin dose } \\
(\mathrm{U} / \mathrm{kg})\end{array}$ & $0.67(0.03)$ & $0.67(0.03)$ & $0.66(0.02)$ \\
\hline $\begin{array}{l}\text { Daily insulin injections } \\
\text { (no.) }\end{array}$ & $1.9(0.1)$ & $2.0(0.1)$ & $2.0(0.1)$ \\
\hline $\begin{array}{l}\text { Patients using regular } \\
\text { insulin (no.) }\end{array}$ & 30 & 40 & 29 \\
\hline $\begin{array}{l}\text { Diabetes related } \\
\text { knowledge score (out } \\
\text { of a maximum of } 37 \text { ) }\end{array}$ & $16(1)$ & $16(1)$ & $17(1)$ \\
\hline $\begin{array}{l}\text { Patients carrying } \\
\text { emergency } \\
\text { carbohydrates (no.) }\end{array}$ & 36 & 31 & 37 \\
\hline $\begin{array}{l}\text { Patients hospitalised } \\
\text { during the year before } \\
\text { the study (no.) }\end{array}$ & 53 & 51 & 46 \\
\hline
\end{tabular}

Values are means (SEM) unless stated otherwise. ${ }^{a}$ Patients with newly diagnosed diabetes excluded; ' significantly different at $p<0.05$ (Kruskal-Wallis 1-way ANOVA); ${ }^{\mathrm{c}}$ data obtained by patient interview

year of the study, all but 3 of the remaining 93 patients attended the intensive diabetes treatment and teaching programme (1 patient had discontinued insulin therapy, 1 patient - a physician - refused, and 1 patient - a professional sportsman - had no time to participate). During the second year of follow-up, another patient died after bowel surgery. Metabolic control of this patient had been good before and during the operation, and his death was unrelated to diabetes. All other patients were re-evaluated at 18 and 24 months. There were no deaths in group B and group C. In group B, 
99 patients were completely evaluated at 6 months, 98 patients at 12 months, 96 at 18 months and 95 at 24 months. Two patients were temporarily in prison, 2 patients were not in Bucharest at the time of the follow-up investigations and 1 patient refused to further participate in the trial. In group $C, 3$ patients at 6 months and 8 patients at 12 months either refused or were unable to come to the follow-up examinations.

\section{Metabolic control and acute complications}

Glycosylated haemoglobin ( $\mathrm{HbA}_{1}$ ) levels (Fig. 1) were unchanged in group A after 1 year of standard therapy,

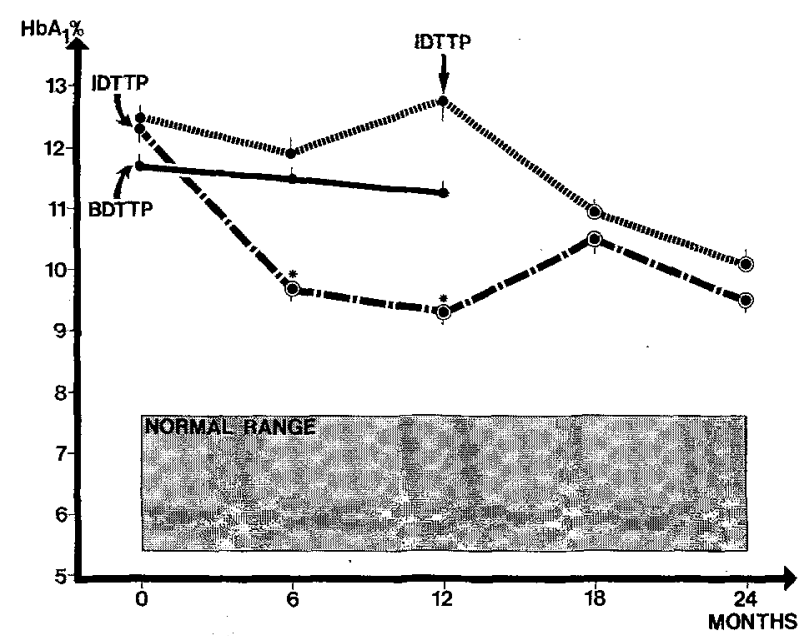

Fig. 1. Glycosylated haemoglobin concentrations $\left(\mathrm{HbA}_{1}\right)$ of the three patient groups during the study. Values are means $\pm S E M$. .... group A, -..- group $B_{3}-$ group $C$. Circles indicate values significantly different from initial values at $p<0.0001$. Asterisks indicate values significantly different from group $A$ and group $C$ at $p<0.0001$. The shaded area represents the mean \pm 2 SD levels in normal control subjects. IDTTP denotes time points at which the groups participated in the intensive diabetes treatment and teaching programme, BDTTP the time point at which the patients of group C participated in the basic diabetes treatment and teaching programme although there was a transient fall at 6 months $(p<$ $0.01)$. The intensive diabetes treatment and teaching programme resulted in a significant decrease of $\mathrm{HbA}_{1}$ levels in group A and group B $(p<0.0001$ compared to baseline values for both groups at all time points of follow-up). A transient increase of $\mathrm{HbA}_{1}$ concentrations was observed in group $\mathrm{B}$ at 18 months $(p<0.0001$ versus 12 months). In group $\mathrm{C}, \mathrm{HbA}_{1}$ values were slightly lower than at entry into the study after 1 year $(p<0.05)$, but the degree of improvement was not of statistical significance in relation to group A $(p=0.062)$. Comparable results were found when patients with newly diagnosed diabetes were excluded from the analyses. In group A, the number of patients with normal $\mathrm{HbA}_{1}$ values was 1 at 12 months, i.e. before the intensive programme, and 4 at 24 months. In group $B$, at entry into the study, no patient had normal $\mathrm{HbA}_{1}$ levels, compared to 12 patients at 12 months and 8 patients at 24 months.

The frequency of severe hypoglycaemia (Table 2) was not significantly different between the 3 groups during the first year of follow-up, either with respect to the number of patients who experienced at least one severe hypoglycaemia or with respect to the total number of severe hypoglycaemias. In group A, the intensive diabetes treatment and teaching programme had no statistically significant influence on the frequency of severe hypoglycaemia when compared to the preceding year of standard therapy. Severe hypoglycaemia, was, however, less frequent in group A than in group B during the first year of intensified therapy $\left(x^{2}=3.848, p=0.050\right.$ for the number of patients with at least 1 severe hypoglycaemia, $Z=2.235, p=0.025$ for the total number of severe hypoglycaemias). In group B the frequency of severe hypoglycaemia decreased significantly during the second year of intensified therapy compared to the first year $(p<0.05)$; during the 2 years of intensified therapy, the total of 39

Table 2. Frequency of severe hypoglycaemia and diabetic ketoacidosis during follow-up

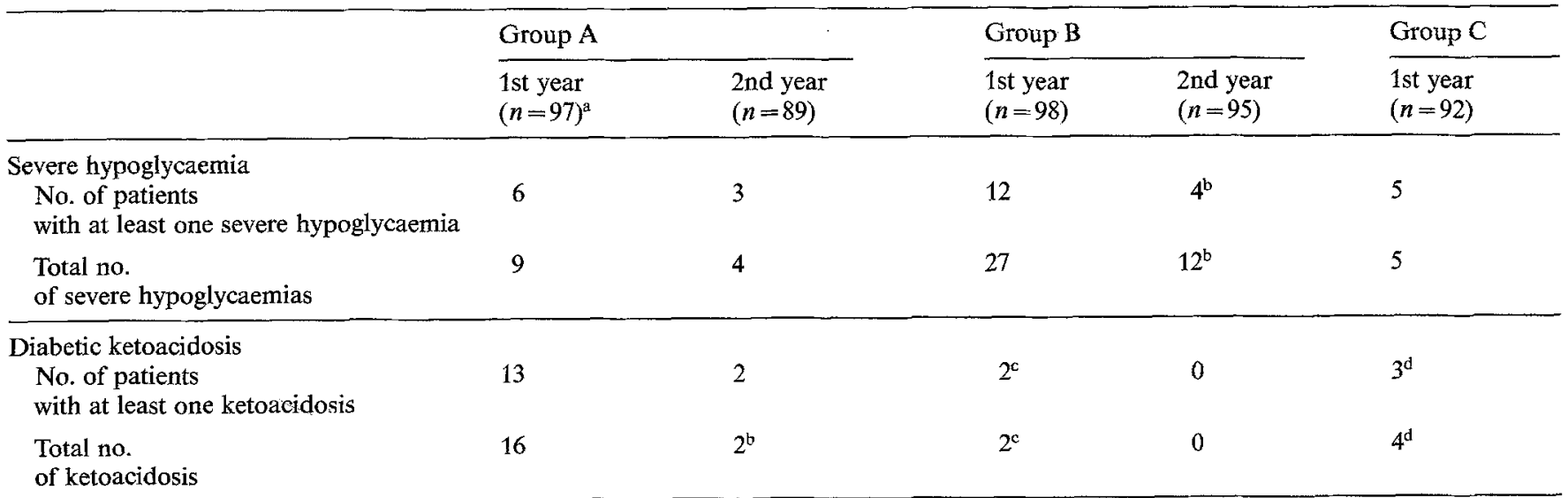

a The four patients who had died during the year were taken into account in the analyses. ${ }^{b}$ Denotes significant difference to preceding year within the group $(p<0.05)$. In comparison to group $A$, ${ }^{\circ}$ denotes a significant difference at $p<0.01$ and ${ }^{\mathrm{d}}$ at $p<0.025$ 
Table 3. Number of daily insulin injections in the three patients groups at 12- and 24 months follow-up

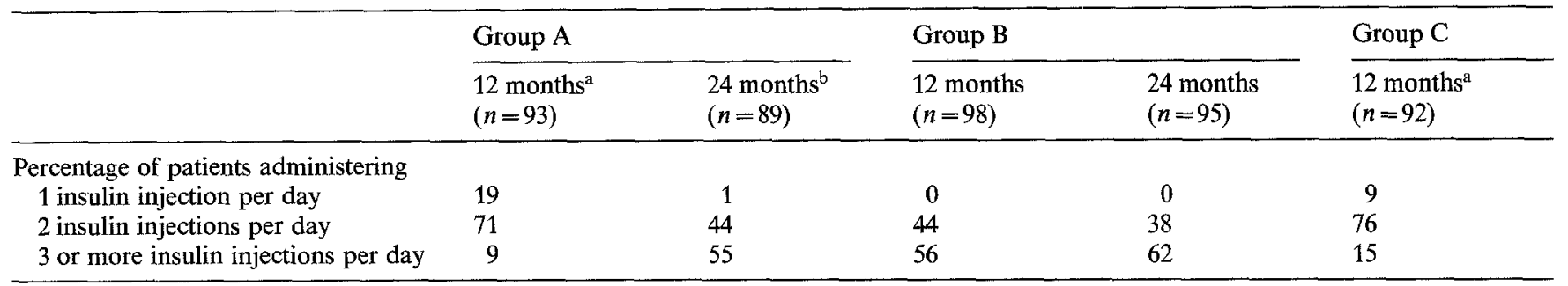

${ }^{\mathrm{a}}$ Denotes significant difference to group B $(p<0.0001)$. ${ }^{\mathrm{b}}$ Denotes significant difference to 12 months results within the group $(p<0.0001)$

severe hypoglycaemias (Table 2) occurred in 13 patients. One patient experienced 20 severe hypoglycaemias (12 during the first year, 8 during the second year), despite increasing his target glucose levels after the first events of severe hypoglycaemia. This patient suffered from chronic hepatitis, and also had reported repeated episodes of severe hypoglycaemia during the years before the study. When patients with newly diagnosed diabetes were excluded from the analyses, among those patients who had participated in the intensive programme 7 of the $23(30 \%)$ who had a prior history of severe hypoglycaemia also had recurrent severe hypoglycaemia (a total of 20 episodes) during the first year of follow-up compared with 4 of the $62(6 \%)$ patients with no prior history of severe hypoglycaemia $(p=0.01)$. Among those who continued the standard treatment, 2 of the $17(12 \%)$ patients who had a prior history of severe hypoglycaemia also had recurrent severe hypoglycaemia during the year of follow-up compared to 4 of the $69(6 \%)$ patients with no prior history of severe hypoglycaemia $(p=0.74)$. Among those who had participated in the basic programme 3 of the 19 $(16 \%)$ patients who had a prior history of severe hypoglycaemia also had recurrent severe hypoglycaemia during the study compared to 2 of the $64(3 \%)$ patients with no prior history of severe hypoglycaemia $(p=0.14)$. When comparing all patients who experienced severe hypoglycaemia during the first year of the study $(n=23)$ with the remaining patients $(n=264)$ those with severe hypoglycaemia had a significantly longer duration of diabetes $(p<0.025)$, and $\mathrm{HbA}_{1}$ levels were significantly lower both at baseline and after 1 year $(p<0.05)$. On the other hand, no associations between the incidence of severe hypoglycaemia and the daily insulin dose $(\mathrm{U} / \mathrm{kg})$, initial C-peptide values or insulin antibody concentrations could be established. Comparable results were obtained when newly diagnosed patients were excluded from the analyses. Thirty-two of the 43 cases of severe hypoglycaemia found in group A and group B patients after the intensive treatment and teaching programme were treated with glucagon injected by relatives without the assistance of a physician. The frequency of diabetic ketoacidosis was significantly reduced by both the intensive and the basic diabetes treatment and teaching programme (Table 2).
Table 4. Daily insulin dose (U/ $\mathrm{kg}$ body weight) in the three patient groups during the study ${ }^{\mathrm{a}}$

\begin{tabular}{llll}
\hline & Group A & Group B & Group C \\
\hline At entry & $0.67(0.03)$ & $0.69(0.03)$ & $0.68(0.03)$ \\
& $n=89$ & $n=87$ & $n=90$ \\
At 6 months & $0.64(0.03)^{\mathrm{c}}$ & $0.74(0.02)^{\mathrm{b}, \mathrm{d}}$ & $0.66(0.02)$ \\
& $n=85$ & $n=86$ & $n=83$ \\
At 12 months & $0.65(0.03)$ & $0.70(0.02)^{\mathrm{c}}$ & $0.67(0.02)$ \\
& $n=80$ & $n=85$ & $n=83$ \\
At 18 months & $0.67(0.02)$ & $0.69(0.02)$ & \\
& $n=79$ & $n=82$ & \\
At 24 months & $0.68(0.02)$ & $0.69(0.02)$ & \\
& $n=79$ & $n=82$ & \\
\hline
\end{tabular}

a Patients with newly diagnosed diabetes are excluded from the analyses. ${ }^{b}$ Denotes significant difference to preceding time point within a group at $p<0.01$, and ${ }^{\circ}$ at $p<0.05$. ${ }^{\mathrm{d}}$ Denotes significant difference between group A and group B $(p<0.01)$ and between group B and group $C(p<0.05)$. Values are means $(\mathrm{SEM})$

Table 5. Body mass index $\left(\mathrm{kg} \cdot \mathrm{m}^{-2}\right)$ in the three patient groups during the study

\begin{tabular}{llll} 
& Group A & Group B & Group C \\
\hline At entry & $21.7(0.3)$ & $21.8(0.2)$ & $21.5(0.2)$ \\
& $n=100$ & $n=100$ & $n=100$ \\
At 6 months & $22.4(0.3)^{\mathrm{a}, \mathrm{c}}$ & $23.3(0.3)^{\mathrm{a}}$ & $22.4(0.2)^{\mathrm{a}, \mathrm{c}}$ \\
& $n=97$ & $n=99$ & $n=97$ \\
At 12 months & $22.4(0.3)^{\mathrm{c}}$ & $23.3(0.3)$ & $22.6(0.2)^{\mathrm{b}, \mathrm{c}}$ \\
& $n=93$ & $n=98$ & $n=92$ \\
At 18 months & $23.0(0.3)^{\mathrm{a}}$ & $23.4(0.3)$ & \\
& $n=89$ & $n=96$ & \\
At 24 months & $23.0(0.3)$ & $23.6(0.3)^{\mathrm{b}}$ & \\
& $n=89$ & $n=95$ & \\
\hline
\end{tabular}

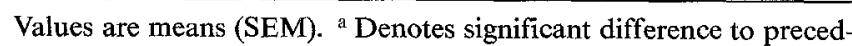
ing time point within a group at $p<0.0001$ and ${ }^{b}$ at $p<0.05 .{ }^{\mathrm{c}} \mathrm{De}-$ notes significant difference to group $\mathrm{B}(p<0.05)$

\section{Insulin treatment}

During the 1 year of standard treatment in group $\mathrm{A}$, there was no significant change in the percentage of patients using regular insulin (30 at baseline, 33 at follow-up), whereas a slight increase was observed after the basic treatment and teaching programme in group C (29 at baseline, 41 at follow-up, $p<0.05$ ). At 
Table 6. Diabetes related knowledge scores during follow-up in the three patient groups

\begin{tabular}{llll}
\hline & Group A & Group B & Group C \\
\hline At entry & $16(1)$ & $16(1)$ & $17(1)$ \\
& $n=100$ & $n=100$ & $n=100$ \\
& & $32(1)$ & $28(1)^{\mathrm{b}}$ \\
At the end of the & & $n=100$ & $n=100$ \\
teaching course & & & \\
At 6 months & $21(1)^{\mathrm{b}, \mathrm{c}}$ & $32(1)$ & $26(1)^{\mathrm{b}}$ \\
& $n=97$ & $n=99$ & $n=97$ \\
At 12 months & $24(1)^{\mathrm{b}, \mathrm{c}}$ & $32(1)$ & $26(1)^{\mathrm{b}}$ \\
& $n=93$ & $n=98$ & $n=92$ \\
At the end of the & $34(1)$ & & \\
teaching course & & & \\
\hline
\end{tabular}

a At the beginning of the study group B participated in the intensive and group $\mathrm{C}$ in the basic diabetes treatment and teaching programme, whereas group A participated in the intensive programme immediately after the 12-month follow-up examination. ${ }^{\mathrm{b}}$ Denotes significant difference to group B $(p<0.0001)$. ${ }^{\circ}$ Denotes significant difference to group $\mathrm{C}(p<0.0001)$. The knowledge scores refer to the number of correct answers, out of a maximum of 37 . Values are means (SEM)

Table 7. Frequency of metabolic self-monitoring in group A and group B after the intensive diabetes treatment and teaching program$\mathrm{me}^{\mathrm{a}}$

\begin{tabular}{lll}
\hline & Group A & Group B \\
\hline At 6 months & & $89(69)$ \\
& & $n=97$ \\
At 12 months & & $72^{\mathrm{b}}(49)^{\mathrm{c}}$ \\
& & $n=94$ \\
& & $70(48)$ \\
At 18 months & $81(61)$ & $n=92$ \\
& $n=83$ & $76(61)^{\mathrm{b}}$ \\
At 24 months & $79(59)$ & $n=92$ \\
\hline
\end{tabular}

a Only measurements recorded in the patients' log books were evaluated. The numbers give the percentage of patients with an average of more than two daily blood or urine glucose measurements, and, in parentheses, the percentage of patients with more than two blood glucose measurements; $n$ gives the number of patients who presented a diabetes $\log$ book. ${ }^{\mathrm{b}}$ Denotes significant difference within the group at $p<0.01$, and ${ }^{\mathrm{C}}$ at $p<0.0001$ the same time, no statistically significant difference was found with respect to the number of daily insulin injections used, either in group A or in group C. In contrast, after participation in the intensive diabetes treatment and teaching programme all patients used regular insulin. The percentage of regular insulin of the total daily insulin dosage was $55 \pm 1$ at 12 months

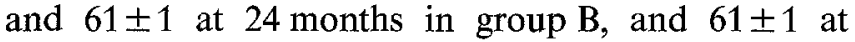
24 months in group A. In addition, significantly more insulin injections per day were applied during intensified therapy than during the other two treatment regimens (Table 3). When patients with newly diagnosed diabetes were excluded from the analyses, daily insulin dosage ( $\mathrm{U} / \mathrm{kg}$ body weight) was decreased during standard treatment $(p<0.05)$, whereas the intensive treatment and teaching programme resulted in a transient increase of daily insulin dosage in group B 6 months after the programme (Table 4).

Body mass index increased signficantly $(p<0.0001)$ in all 3 groups during the first 6 months of the study (Table 5). The increase was greater in group B $(p<$ 0.05 ) than in the other 2 groups. An additional significant increase $(p<0.0001)$ was observed in group A 6 months after participation in the intensive diabetes treatment and teaching programme. Comparable results were obtained by excluding patients with newly diagnosed diabetes from the analyses.

\section{Diabetes related knowledge and parameters of patient compliance}

Diabetes related knowledge increased significantly $(p<0.0001)$ in all groups during the first year of the study (Table 6). The highest knowledge scores were found after the patients' participation in the intensive treatment and teaching programme both in group A and in group B. The percentage of patients carrying emergency carbohydrates was significantly increased $(p<0.0001)$ in all groups at the 1-year follow-up (Group A: 75\%, group B: 97\%, group C: 88\%). Almost all patients of the intensive treatment groups had a diabetes $\log$ book (Table 7). Analyses of the patients' entries in the log books showed that on average $80 \%$ of

Table 8. Hospitalisations of the three patient groups during the first and second year of follow-up

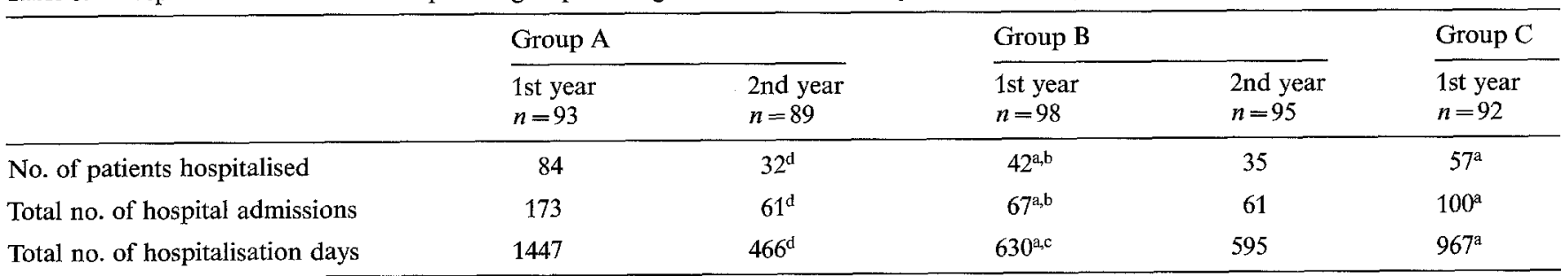

${ }^{\mathrm{a}}$ Denotes significant difference to group A $(p<0.0001)$. ${ }^{\mathrm{b}}$ Denotes significant difference to group $\mathrm{C}$ at $p<0.005$ and ${ }^{\mathrm{c}}$ at $p<0.001$. ${ }^{\mathrm{d}}$ Denotes significant change within group A at $p<0.0001$ 
the patients performed measurements of either blood or urine glucose more than twice daily, and about $60 \%$ of the patients performed blood glucose measurements more than twice daily. In group C, $90 \%$ of the patients at 6 months and $79 \%$ of the patients at 12 months reported daily glucosuria testing.

\section{Hospitalisations}

Hospital admissions as well as hospitalisation days were significantly reduced after both the intensive and the basic treatment and teaching programme (Table 8). Patients who participated in the intensive programme also had significantly lower hospitalisation rates than patients in the basic programme.

\section{Discussion}

Because of the fact that in Rumania, until the time of this study, no materials for blood glucose self-monitoring were available, and due to the conditions of the centralised health care system of that country, it was possible to document the introduction of an intensive insulin treatment and teaching programme by a prospective controlled trial that enrolled patients who were not selected by a special interest to participate in a clinical investigation, or a high motivation to achieve good metabolic control, or social or educational status. Patients who might be regarded as particularly difficult to treat, e.g. those with a history of repeated episodes of severe hypoglycaemia or ketoacidosis, were included in the study, as well as patients who still had some residual insulin secretion or patients with newly diagnosed diabetes. These broad recruitment criteria contribute to a high generalisibility or external validity [10] of the results of the study with regard to Type 1 diabetic patients aged between 15 and 40 years without advanced diabetic late complications. The allocation procedure chosen was group rather than individual randomisation. The latter was discarded as inappropriate for the present investigation, since the introduction and performance of a Monday to Friday group treatment and teaching programme requires structural and organisational changes within the diabetes ward. For studies evaluating educational and health care programmes group randomisation has been suggested as superior to individual randomisation whenever patients are housed in the same ward [10], as is the case in the present investigation. Nevertheless, group randomisation also carries hazards. By assigning consecutively admitted patients to the three therapy regimins, the first patients recruited might have had more severe diabetes or might have been more difficult to treat; they could consequently have been more frequently hospitalised and thus had a greater chance of being included in the first group. There were, however, no significant differences between relevant clinical da- ta of the three patient groups at entry into the study except for glycosylated haemoglobin $\left(\mathrm{HbA}_{1}\right)$ values, which were slightly lower in group $\mathrm{C}$. The risk of confounding was minimised by enrolling the control (group A) patients, after 1 year of standard therapy, in the intensive diabetes treatment and teaching programme and following them up for another year on the intensified regimen. In fact, the outcome of the intensive programme was almost identical in group A and group B. Only severe hypoglycaemia was found significantly more often in group B during the first year of intensified treatment. Since the frequency of this acute complication was significantly reduced in group B during the second year of follow-up, these results appear to reflect an increased experience in the performance of the new therapeutic regimen, rather than confounding differences between the groups.

The standard treatment strategies of the Bucharest hospital may not be representative of highly developed communities at present, since no metabolic self-monitoring was advised. On the other hand, even in Western European countries like Germany, or in Japan, routine treatment of Type 1 diabetes did not include any metabolic self-monitoring up to the early eighties, and patients were advised not to alter insulin dosages unless previously contacting their physicians. These regimens are still practiced in most parts of the world, and even in some regions of Western Europe. In the present study, the results of the standard treatment were alarming. During 1 year, 4 patients died, 1 in a state of hypoglycaemia and 3 after admission to the hospital in severe ketoacidosis associated with infectious diseases. Thirteen partients had experienced a total of 16 cases of diabetic ketoacidosis during the first year of follow-up. Comparably high incidence rates of ketoacidosis may occasionally still be found in technologically more advanced regions. Thus, in a group of 161 Type 1 diabetic patients, "conventionally" treated in a specialised diabetes centre in the United States of America, 14 subjects had a total of 29 events of ketoacidosis during an observation period of 18 months [18]. In addition, comparably high $\mathrm{HbA}_{1}$ values as those found in the present study at baseline have been reported from countries where glucosuria testing and adaptation of insulin dosages by the patient have been part of insulin treatment for decades [19, 20].

The third group of patients (group C), who participated in the basic treatment and teaching programme, may be a more representative "control" group to many Western countries at present. These patients had the opportunity to monitor glucosuria and acetonuria, and were trained to adapt insulin therapy by themselves. During the 1-year follow-up, no death occurred in this patient group, and the frequency of ketoacidosis was significantly lower than in the standard treatment group. This finding demonstrates that a significant improvement of diabetes care, i. e. the reduction of acute complications and hospitalisations, can be readily 
achieved by the provision of simple, qualitative materials for urine analysis by the patients when associated with a structured group teaching programme. Similarly low incidence rates of ketoacidosis have been found in conventionally treated Type 1 diabetic patients who participated in clinical research studies in the USA and Great Britain [18, 21, 22]. However, $\mathrm{HbA}_{1}$ values were not influenced by the basic programme when compared to the standard treatment regimen.

In contrast, the intensive diabetes treatment and teaching programme resulted in a significant improvement of $\mathrm{HbA}_{1}$ concentrations for up to 2 years in group B. A similar effect was observed in group A during the 1-year follow-up. During intensified therapy $\mathrm{HbA}_{1}$ values were lowered on average by 2 to $3 \%$. This demonstrates an improvement in metabolic control as significant as previously obtained in selected and intensively treated research patients [23,24]. Despite this overall substantial reduction of mean $\mathrm{HbA}_{1}$ levels, only $9 \%$ of the patients had $\mathrm{HbA}_{1}$ values within the normal range after 1 year of intensified therapy. Nevertheless, the improvement of glycaemic control achieved should be of paramount clinical relevance: recent studies have shown that glycosylated haemoglobin reductions of as little as 1 to $2 \%$ may be sufficient to at least delay the progression of early manifestations of diabetic late complications [23-25].

It is impossible to differentiate which of the various changes that were associated with the introduction of the intensive treatment and teaching programme was most relevant for the long-term outcome. Participation in a study can by itself change physician and patient behavior. Accordingly, diabetes-related knowledge scores and the percentage of patients carrying emergency carbohydrates - a reliably and easily measurable parameter of patient compliance - also increased to a remarkable degree during standard treatment. Nevertheless, metabolic control improved only transiently and was unchanged after 1 year when compared to the baseline situation. Thus, a mere "study effect" can be excluded as a major factor. This conclusion is in accordance with a previous study, which showed that solely increasing physicians' attention even when associated with the introduction of blood glucose self-monitoring fails to improve metabolic control beyond 6 months [26]. Likewise, the differences concerning the insulin preparations used between the study groups can be excluded as a confounding factor, since it has been reported that changing patients from beef insulins to purer insulins was, if anything, associated with a deterioration in metabolic control, at least in one center [20]. Thus, the intensive programme evaluated in this study has to be regarded as an integrated approach including treatment strategies, the use of particular materials, and patient training. As discussed in a previous review article [9], any effort to study only one single element of such a comprehensive programme of diabetes care has to fail.
The major concern regarding intensified insulin strategies has been related to the potential hazard of severe hypoglycaemia [5, 6]. In the present study, patients of group B had a 2- to 2.4-fold greater risk of experiencing at least one severe hypoglycaemia during the first year of intensified therapy than patients in the other two groups, but the differences were statistically not significant. In the same group significantly fewer episodes of severe hypoglycaemia occurred during the second year of follow-up. In group A, which was followed both for 1 year on standard treatment and thereafter for 1 year on intensified treatment, the frequency of severe hypoglycaemia was halved by the intensive programme, although this decrease was also not statistically significant. These findings document that an improvement of $\mathrm{HbA}_{1}$ values is not necessarily associated with an increased risk of severe hypoglycaemia. Patients with a history of repeated episodes of severe hypoglycaemia were not excluded from the protocol. In fact, one patient of group B, who had a total of 20 cases of severe hypoglycaemia during the 2-year follow-up despite increasing glycaemic target goals, had already had a comparable frequency of severe hypoglycaemia before the study. In accordance with a recent report from the DCCT trial [27] the occurrence of severe hypoglycaemia before the study was a risk factor for this event after the intervention. This was likewise true for the intensively treated patients and for the other patient groups, although in the latter ones the results were not statistically significant due to the small numbers of patients who experienced severe hypoglycaemia. Overall, the frequency of severe hypoglycaemia in the intensively treated patients, and also in the patients who participated in the basic treatment and teaching programme, were low in comparison to other data from the literature $[22,24,27-29]$. The quality of patient education appears to be a major factor for this favourable outcome as has been discussed previously $[8,9]$. However, since only a minor percentage of the intensively treated patients had normal $\mathrm{HbA}_{1}$ levels at follow-up, it cannot be excluded that further lowering $\mathrm{HbA}_{1}$ values would have resulted in a higher incidence rate of severe hypoglycaemia. Seventy-four percent of the cases of severe hypoglycaemia which occurred during intensified therapy were successfully treated with glucagon. This is an even higher proportion than has been found in patients who participated in the same programme in Düsseldorf [8].

It has been argued that intensive insulin regimens with frequent blood glucose monitoring may be acceptable only for a minor percentage of patients [6]. In the present study, under the condition of multiple daily injections of regular insulin and immediate adaptations of insulin dosage based upon actual results of blood glucose self measurements, patients were offered the opportunity to adopt a more liberalised diet [11-13] without the risk of metabolic deterioration. Under these circumstancies more than half of the patients ad- 
ministered at least three insulin injections per day, and about $60 \%$ of the patients recorded more than 2 daily blood glucose measurements for up to 2 years. Based upon earlier publications $[9,11,12]$ we suggest that the possibility to liberalise diet represented a strong motivation for the patients of this study to accept the intensification of their therapy. Body mass indices rose during the first 6 months of the study in all patient groups. This probably reflects restabilisation of the decompensated metabolism. During intensified therapy, the increase was more pronounced than during the other two treatment regimens, but body mass indices remained well within desirable limits.

Hospitalisation days were significantly lowered following the patients' participation in the intensive diabetes treatment and teaching programme, and also, to a lesser extent, in patients who attended the basic programme. Overall, hospital admissions were high when compared to other countries, especially the United States [30]. Regional differences in the structure and financing of the health care system appear to be the main reasons for these discrepancies. However, similar reductions in hospitalisation days have been found in patients who participated in the intensive treatment and teaching programme either of Bucharest or Düsseldorf [31].

No systematic evaluation of the frequency of outpatient contacts has been performed. All patients were required to regularly come to the diabetes center in order to get the materials and prescriptions for their therapy. During intensified treatment periods outpatient contacts were more intensive, since the patients had the opportunity of consulting the members of the teaching team by phone. On the other hand, patients in the other two treatment regimens were hospitalised more often. Patient contacts with members of the health care team during hospitalisations cannot be systematically quantified.

There has been doubt that intensification of diabetes treatment is generally practicable because of the necessity of additional and qualified personnel. In Bucharest, two physicians and two nurses were specially trained to establish and perform the programme, and to take care of the patients during follow-up. Except for the first few months, these persons had other obligations as well. This is in accordance with the organisational structure of the diabetes ward of the University Hospital of Düsseldorf, where at present an average of 400 to 500 patients per year participate in the 5-day treatment and teaching programme for Type 1 diabetes; about 200 additional patients participate in a comparable programme for older patients with insulin-dependent diabetes. Two full-time nurses, two part-time dietitians and one physician are in charge of these patients.

In conclusion, the present investigation demonstrates the substantial impact of an intensive insulin treatment and teaching programme for Type 1 diabetic patients. Glycosylated haemoglobin $\left(\mathrm{HbA}_{1}\right)$ values were significantly lowered for up to 2 years of followup without increasing the risk of severe hypoglycaemia. Ketoacidosis was almost eliminated, and hospitalisation days were considerably decreased. The study shows that intensified conventional insulin therapy aiming at near-normoglycaemia is safe, feasible and acceptable for Type 1 diabetic patients under the condition that the insulin treatment is based upon structured and comprehensive training of the patient in the autonomous management of his or her disease.

Acknowledgements. The study has been supported by the Peter Klöckner Stiftung, Duisburg and the Bundesminister des Auswärtigen und für Jugend, Familie, Frauen und Gesundheit (Bonn, FRG). The materials for metabolic self-monitoring, insulin preparations and plastic syringes used in the course of the study were provided by Boehringer Mannheim (Mannheim, FRG), Novo-Industri (Mainz, FRG) and Becton-Dickinson (Heidelberg, FRG). In addition, we gratefully acknowledge the dedicated cooperation of Ms. A.Albules$\mathrm{cu}$, R. N., and Ms. A. Minea, R. N., and the assistance of Mr. U. Bott in performing the statistical analyses of the data.

\section{References}

1. Borch-Johnsen K, Andersen PK, Deckert T (1985) The effect of proteinuria on relative mortality in Type 1 (insulin-dependent) diabetes mellitus. Diabetologia 28: 590-596

2. Jovanovic L, Peterson CM, Saxena BB, Dawood MY, Saudek CD (1980) Feasibility of maintaining normal glucose profiles in insulin-dependent pregnant diabetic women. Am J Med 68: 105-112

3. Schiffrin A, Belmonte MM (1982) Comparison between continuous subcutaneous insulin infusion and multiple injections of insulin. A one-year prospective study. Diabetes 31: 255-264

4. Reeves ML, Seigler DE, Ryan EA, Skyler JS (1982) Glycemic control in insulin-dependent diabetes mellitus. Comparison of outpatient intensified conventional therapy with continuous subcutaneous insulin infusion. Am J Med 72: 673-680

5. Unger RH (1982) Meticulous control of diabetes: benefits, risks, and precautions. Diabetes 31: 479-483

6. The DCCT Research Group (1986) The diabetes control and complications trial (DCCT). Design and methodologic considerations for the feasibility phase. Diabetes $35: 530-545$

7. Mühlhauser I, Jörgens V, Berger M, Graninger W, Gürtler W, Hornke L, Kunz A, Schernthaner G, Scholz V, Voss HE (1983) Bicentric evaluation of a teaching and treatment programme for Type 1 (insulin-dependent) diabetic patients: improvement of metabolic control and other measures of diabetes care for up to 22 months. Diabetologia 25: 470-476

8. Mühlhauser I, Berger M, Sonnenberg GE, Koch J, Jörgens V, Schernthaner G, Scholz V (1985) Incidence and management of severe hypoglycemia in 434 adults with insulin-dependent diabetes mellitus. Diabetes Care 8: 268-273

9. Assal JP, Mühlhauser I, Pernet A, Gfeller R, Jörgens V, Berger M (1985) Patient education as the basis for diabetes care in clinical practice and research. Diabetologia 28: 602-613

10. Kramer MS, Shapiro SH (1984) Scientific challenges in the application of randomized trials. JAMA 252: 2739-2745

11. Chantelau EA, Sonnenberg GE, Stanitzek-Schmidt I, Best F, Altenähr H, Berger M (1982) Diet liberalization and metabolic control in type-1 diabetic outpatients treated by continuous subcutaneous insulin infusion. Diabetes Care 5: 612-616

12. Chantelau EA, Frenzen A, Gösseringer G, Hansen I, Berger M (1987) Intensive insulin therapy justifies simplification of the dia- 
betes diet: a prospective study in insulin-dependent diabetics. Am J Clin Nutr 45: 958-962

13. Chantelau EA, Gösseringer G, Sonnenberg GE, Berger M (1985) Moderate intake of sucrose does not impair metabolic control in pump-treated diabetic out-patients. Diabetologia 28: 204-207

14. Mühlhauser I, Koch J, Berger M (1985) Pharmacokinetics and bioavailability of injected glucagon: differences between intramuscular, subcutaneous and intravenous administration. Diabetes Care $8: 39-42$

15. Seidel A (1987) Comparison of methods of urine glucose measurement. M. D. Thesis, University of Düsseldorf, FRG

16. Ionescu-Tîrgoviște C, Mincu I, Simionescu L, Cheţa D, Mirodon Z, Sântu E, Popa E, Bîrnea A (1984) Disappearance rate of insulin antibodies after discontinuing insulin treatment in 42 Type 2 (non-insulin-dependent) diabetic patients. Diabetologia 27: $592-595$

17. Siegel S (1976) Nichtparametrische statistische Methoden. Fachbuchhandlung für Psychologie, Frankfurt

18. Mecklenburg RS, Benson EA, Benson JW, Fredlund PN, Guinn T, Metz RJ, Nielsen RL, Sannar CA (1984) Acute complications associated with insulin infusion pump therapy. Report of experience with 161 patients. JAMA 252: 3265-3269

19. Klein R, Klein BEK, Davis MD (1983) Is cigarette smoking associated with diabetic retinopathy? Am J Epidemiol 118: 228-238

20. Peacock I, Tattersall RB, Taylor A, Douglas CA, Reeves WG (1983) Effects of new insulins on insulin and C-peptide antibodies, insulin dose, and diabetic control. Lancet 1: 149-152

21. The Kroc Collaborative Study Group (1984) Blood glucose control and the evolution of diabetic retinopathy and albuminuria. A preliminary multicenter trial. N Engl J Med 311: 365-372

22. Bending JJ, Pickup JC, Keen H (1985) Frequency of diabetic ketoacidosis and hypoglycemic coma during treatment with continuous subcutaneous insulin infusion. Am J Med 79: 685-691

23. Feldt-Rasmussen B, Mathiesen ER, Deckert T (1986) Effect of two years of strict metabolic control of progression on incipient nephropathy in insulin-dependent diabetes. Lancet 2: 1300-1304

24. Dahl-Jørgensen KD, Brinchmann-Hansen O, Hanssen KF, Ganes T, Kierulf P, Smeland E, Sandvik L, Aagenaes $\varnothing(1986)$ Effect of near normoglycaemia for two years on progression of early diabetic retinopathy, nephropathy and neuropathy: the Oslo study. Br Med J 293: 1195-1199
25. Hanssen KF, Dahl-Jørgensen K, Lauritzen T, Feldt-Rasmussen B, Brinchmann-Hansen O, Deckert T (1986) Diabetic control and microvascular complications: the near-normoglycaemic experience. Diabetologia 29: 677-684

26. Worth R, Home PD, Johnston DG, Anderson J, Ashworth L, Burrin JM, Appleton D, Binder C, Alberti KGMM (1982) Intensive attention improves glycaemic control in insulin-dependent diabetes without further advantage from home blood glucose monitoring: results of a controlled trial. $\mathrm{Br}$ Med J 285: $1233-1240$

27. The DCCT Research Group (1987) Diabetes control and complications trial (DCCT): results of feasibility study. Diabetes Care 10: $1-19$

28. Basdevant A, Costagliola D, Lanöe JL, Goldgewicht C, Triomphe A, Metz F, Denys H, Eschwege E, Fardeau M, Tchobroutsky $\mathrm{G}$ (1982) The risk of diabetic control: a comparison of hospital versus general practice supervision. Diabetologia 22: 309-314

29. Potter J, Clarke P, Gale EAM, Dave SH, Tattersall RB (1982) Insulin-induced hypoglycaemia in an accident and emergency department: the tip of an iceberg? Br Med J 285: 1180-1182

30. Miller LV, Goldstein J (1972) More efficient care of diabetic patients in a county-hospital setting. N Engl J Med 286: 1388-1391

31. Mühlhauser I, Klemm AB, Boor B, Scholz V, Berger M (1986) Krankenhausaufenthalts- und Arbeitsunfähigkeitszeiten bei Patienten mit Typ-I-Diabetes. Einfluß eines Diabetes-Behandlungsund Schulungsprogramms. Dtsch Med Wochenschr 111: $854-857$

Received: 20March 1987

and in revised form: 21 July 1987

Dr. Ingrid Mühlhauser

Medizinische Klinik der Universität Düsseldorf

Abteilung für Stoffwechsel und Ernährung

Moorenstraße 5

D-4000 Düsseldorf

FRG 